\title{
Domiciliary nasal intermittent positive pressure ventilation in severe COPD: effects on lung function and quality of life
}

\author{
C. Perrin, Y. El Far, F. Vandenbos, R. Tamisier, M.C. Dumon, F. Lemoigne, J. Mouroux, B. Blaive
}

Domiciliary nasal positive pressure ventilation in severe COPD: effects on lung function and quality of life. C. Perrin, Y. El Far, F. Vandenbos, R. Tamisier, M.C. Dumon, F. Lemoigne, J. Mouroux, B. Blaive. (ERS Journals Ltd 1997.

ABSTRACT: The aim of this study was to determine the effect of domiciliary nasal intermittent positive pressure ventilation (NIPPV) on lung function and quality of life in hypercapnic patients with chronic obstructive pulmonary disease (COPD).

Fourteen hypercapnic COPD patients in a stable clinical condition were evaluated in a prospective study of domiciliary NIPPV plus long-term oxygen therapy. Baseline data obtained during a 4 week run-in period were compared with measurements at the end of the 6 month study period. Spirometric parameters, arterial blood gas tensions, and quality of life were assessed. Quality of life was measured using the St George's Respiratory Questionnaire (SGRQ) and the French version of the Nottingham Health Profile (FVNHP).

All patients completed 6 months of domiciliary NIPPV. Gastro-intestinal inflation was reported by eight patients. Daytime arterial oxygen tension and arterial carbon dioxide tension, improved after therapy. During the NIPPV study period, the total SGRQ score and impacts score both improved significantly; significant improvements were also noted in the total FVNHP score and the physical mobility, emotional reactions, and energy component scores.

Domiciliary nasal intermittent positive pressure ventilation combined with long-term oxygen therapy has been found to improve blood gases in spontaneous ventilation, as well as the quality of life of patients with chronic obstructive pulmonary disease.

Eur Respir J 1997; 10: 2835-2839.
Service de Pneumologie et Réanimation Respiratoire, Hôpital Pasteur, Centre Hospitalier et Universitaire de Nice, France.

Correspondence: C. Perrin

Service de Pneumologie

Allergologie et Réanimation Respiratoire

Hôpital Pasteur

C.H.U. de Nice

B.P. 69

30, Voie Romaine

06002 Nice Cedex 1

France

Keywords: Chronic obstructive pulmonary disease

domiciliary care

lung function

nasal intermittent positive pressure venti-

lation

quality of life

Received: September 241996

Accepted after revision September 71997
Nasal intermittent positive pressure ventilation (NIPPV) is being increasingly recognized as an effective means of ventilatory support for patients with respiratory failure due to neuromuscular disease or chest wall deformity [1]. Although physiological benefits such as a reduction in the workload on the respiratory muscles have been demonstrated with NIPPV in cases of severe chronic obstructive pulmonary disease (COPD) [2], little is known about the impact of NIPPV on these patients' survival, quality of life, or lung function $[3,4]$. Several studies have reported varying degrees of improvement in lung function [5-7] and quality of life [6, 7] with NIPPV. Additional investigations have thus been recommended to determine the potential value of NIPPV in hypercapnic COPD patients [3].

This prospective study assessed the effect of NIPPV plus long-term oxygen therapy (LTOT) on lung function and quality of life in patients with stable hypercapnic respiratory failure due to COPD, using two validated health questionnaires. Follow-up was continued for 6 months.

\section{Subjects and methods}

\section{Patients}

Fourteen COPD patients (eight male, six female), mean age 65 yrs (range 47-79), with severe airflow limitation were enrolled. Patient characteristics are listed in tables 1 and 2. Five patients had been established on LTOT for over $1 \mathrm{yr}$ prior to recruitment; their mean \pm SD blood gas levels in room air on entry to the study were arterial carbon dioxide tension $\left(P \mathrm{a}, \mathrm{CO}_{2}\right) 7.2 \pm 0.3 \mathrm{kPa}$, arterial oxygen tension $\left(P a, O_{2}\right) 7 \pm 0.8 \mathrm{kPa}$, and $\mathrm{pH}$ was $7.39 \pm 0.008$. The other nine patients had been hospitalized in our department 2-3 months before inclusion in the study for acute respiratory decompensation; six of these nine patients had required intubation/assisted ventilation. Following this episode of acute exacerbation, oxygen therapy was continued at home because of nocturnal or exertional aggravation of hypoxaemia. At the time of initiation of mechanical ventilation by nasal mask, all patients were clinically stable, as confirmed by a variation of less than $10 \%$ in arterial blood gas tensions and forced expiratory volume in one second (FEV1), at the beginning and at the end of a 4 week run-in period. All patients were hypoxaemic and hypercapnic at the time of recruitment $\left(\mathrm{pH} 7.38 \pm 0.01 ; \mathrm{Pa}_{\mathrm{a}} \mathrm{CO}_{2} 7.8 \pm 0.8\right.$ $\mathrm{kPa} ; \mathrm{Pa}, \mathrm{O}_{2} 7.8 \pm 0.7 \mathrm{kPa}$; arterial oxygen saturation $\left(\mathrm{Sa}, \mathrm{O}_{2}\right)$ $89.2 \pm 2.9 \%)$.

\section{Study design}

The patients entered in this prospective study first completed a 4 week run-in period of standard care (including 
Table 1. - Baseline characteristics of the study population

\begin{tabular}{|c|c|c|c|c|c|c|c|c|c|c|}
\hline \multirow{2}{*}{$\begin{array}{l}\text { Case } \\
\text { No. }\end{array}$} & \multirow{2}{*}{$\begin{array}{l}\text { Age } \\
\text { yrs }\end{array}$} & \multirow[t]{2}{*}{ Sex } & \multirow[t]{2}{*}{ Diagnosis } & \multirow{2}{*}{$\begin{array}{c}\text { Prior } \\
\text { LTOT }\end{array}$} & \multirow{2}{*}{$\begin{array}{l}\text { VC } \\
\text { L }\end{array}$} & \multirow{2}{*}{$\begin{array}{c}\text { FEV1 } \\
\text { L }\end{array}$} & \multirow{2}{*}{$\begin{array}{c}\text { TLC } \\
\text { L }\end{array}$} & \multicolumn{3}{|c|}{ Arterial blood gases* } \\
\hline & & & & & & & & $\mathrm{pH}$ & $P \mathrm{a}, \mathrm{CO}_{2}$ & $\mathrm{~Pa}, \mathrm{O}_{2}$ \\
\hline 1 & 75 & M & COB & Yes & 3.06 & 0.88 & 5.90 & 7.40 & 7.6 & 6.6 \\
\hline 2 & 55 & M & COB & Yes & 2.17 & 0.67 & 6.06 & 7.42 & 7.6 & 7.6 \\
\hline 3 & 62 & M & $\mathrm{COB}$ & Yes & 2.50 & 0.63 & 4.17 & 7.39 & 6.6 & 7.6 \\
\hline 4 & 62 & M & COB & Yes & 1.77 & 0.72 & 4.00 & 7.38 & 7.4 & 6.8 \\
\hline 5 & 68 & $\mathrm{~F}$ & $\mathrm{TS}$ & No & 0.80 & 0.43 & 1.30 & & & \\
\hline 6 & 67 & $\mathrm{~F}$ & TS & No & 1.00 & 0.43 & 2.68 & & & \\
\hline 7 & 57 & M & COB & No & 2.80 & 0.95 & 5.66 & & & \\
\hline 8 & 71 & M & $\mathrm{COB}$ & No & 2.29 & 0.73 & 5.82 & & & \\
\hline 9 & 47 & $\mathrm{~F}$ & $\mathrm{COB}$ & Yes & 1.31 & 0.53 & 3.78 & 7.41 & 7.3 & 7.7 \\
\hline 10 & 73 & $\mathrm{~F}$ & $\mathrm{COB}$ & No & 1.23 & 0.52 & 3.99 & & & \\
\hline 11 & 63 & M & $\mathrm{COB}$ & No & 2.73 & 1.16 & 5.14 & & & \\
\hline 12 & 67 & M & COB & No & 1.45 & 0.74 & 2.62 & & & \\
\hline 13 & 63 & $\mathrm{~F}$ & $\mathrm{COB}$ & No & 2.79 & 0.66 & 6.63 & & & \\
\hline 14 & 79 & $\mathrm{~F}$ & $\mathrm{TS}$ & No & 0.98 & 0.46 & 2.77 & & & \\
\hline Mean & 65 & & & & 2.2 & 0.75 & 4.9 & 7.40 & 7.3 & 7.2 \\
\hline SD & 8 & & & & 0.6 & 0.18 & 1.2 & 0.01 & 0.3 & 0.4 \\
\hline
\end{tabular}

*Arterial blood gas values 12 months before entry into the study. COB: chronic obstructive bronchitis; TS: tuberculous sequelae; VC: vital capacity; FEV1: forced expiratory volume in one second; TLC: total lung capacity; M: male; F: female; LTOT: long-term oxygen therapy; $\mathrm{Pa}_{\mathrm{a}, \mathrm{CO}_{2}}$ : arterial carbon dioxide tension; $\mathrm{Pa}, \mathrm{O}_{2}$ : arterial oxygen tension.

Table 2. - Daytime arterial blood gas values immediately prior to the initiation and after 6 months of nasal intermittent positive pressure ventilation (NIPPV) breathing room air at rest

\begin{tabular}{lcccccc}
\hline \multirow{2}{*}{$\begin{array}{c}\text { Case } \\
\text { No. }\end{array}$} & NIPPV & \multicolumn{2}{c}{$\mathrm{P}_{\mathrm{a}, \mathrm{CO}_{2}}$} & & \multicolumn{2}{c}{$P \mathrm{a}, \mathrm{O}_{2}$} \\
\cline { 6 - 7 } \cline { 6 - 7 } \cline { 5 - 6 } & & Baseline & Follow-up & & Baseline & Follow-up \\
\hline 1 & $\mathrm{D}$ & 7.2 & 5.4 & & 6.5 & 7.3 \\
2 & $\mathrm{D}$ & 9.6 & 8.0 & & 7.3 & 8.0 \\
3 & $\mathrm{D}$ & 7.3 & 6.5 & & 7.3 & 8.4 \\
4 & $\mathrm{D}$ & 8.6 & 6.8 & & 6.4 & 6.9 \\
5 & $\mathrm{~N}$ & 8.0 & 6.5 & & 8.0 & 9.3 \\
6 & $\mathrm{~N}$ & 6.5 & 6.5 & & 8.9 & 9.2 \\
7 & $\mathrm{~N}$ & 8.0 & 6.2 & & 8.0 & 10.0 \\
8 & $\mathrm{~N}$ & 7.3 & 6.5 & & 8.4 & 10.1 \\
9 & $\mathrm{~N}$ & 8.9 & 6.6 & & 7.4 & 9.3 \\
10 & $\mathrm{~N}$ & 8.1 & 6.8 & & 8.1 & 10.1 \\
11 & $\mathrm{~N}$ & 6.5 & 5.3 & & 8.0 & 8.6 \\
12 & $\mathrm{~N}$ & 7.3 & 5.0 & & 8.6 & 10.0 \\
13 & $\mathrm{~N}$ & 8.1 & 5.7 & & 8.6 & 9.4 \\
14 & $\mathrm{~N}$ & 8.1 & 6.5 & & 8.6 & 9.4 \\
\hline Mean & & 7.8 & 6.3 & & 7.8 & 9.0 \\
S D & & 0.8 & 0.7 & & 0.7 & 0.9 \\
\hline
\end{tabular}

$\mathrm{Pa}_{\mathrm{a}} \mathrm{CO}_{2}$ : arterial carbon dioxide tension; $\mathrm{Pa}_{\mathrm{a}} \mathrm{O}_{2}$ : arterial oxygen tension; D: daytime; N: nocturnal.

LTOT) during which baseline measurements were obtained. Initial evaluation included two all-night polysomnography studies consisting of continuous monitoring of oronasal airflow, chest and abdominal wall movement, oxygen saturation, electrocardiogram, electro-oculograms, submental electromyograms, and electroencephalograms recorded on a polygraph (Hypnotrace, Techneme, Nice, France). No sleep staging could be performed. None of the patients had any evidence of obstructive sleep apnoea, defined as more than five apnoeic or hypopnoeic episodes $\cdot h^{-1}$ [7]. The run-in period was followed by a 6 month study period during which patients received oxygen therapy plus nocturnal NIPPV delivered by a volume preset ventilator (Eole 2NA, Saime, Savigny-le-Temple, France).
All ventilators were operated in the assist/control mode. Patients used commercial nasal masks (Respironics, Inc., Murrysville, PA, USA). LTOT was delivered at a constant flow rate of 1-2 L.min-1 via nasal cannulae, and supplemental oxygen was entrained through the ventilator during NIPPV.

At the beginning of the study, all patients were acclimatized to NIPPV in the hospital for a period of 5 days. During hospitalization, they were instructed in the use of the ventilator and the mask, and the ventilator settings were adjusted for the patients' comfort and to maximize gas exchange (tidal volume: $20 \mathrm{~mL} \cdot \mathrm{kg}^{-1}$; respiratory frequency: $12-14$ breaths $\cdot \mathrm{min}^{-1}$, inspiratory/expiratory ratio 1-1:2). After initiation of NIPPV, they were seen as inpatients for $24 \mathrm{~h}$ every month, at which time clinical status, nocturnal $\mathrm{Sa}_{\mathrm{a}} \mathrm{O}_{2}$, and awake arterial blood gases on NIPPV were assessed. Minor adjustments were made to ventilator settings when required. During hospitalization, therapeutic compliance was determined by systematic readings of the integrated respirator timers.

\section{Spirometry and arterial blood gases}

Static lung volume, FEV1, and vital capacity (VC) were measured during initial evaluation and at the end of the 6 month study period. Static lung volumes were determined by a constant-volume whole body plethysmograph (Jaeger Masterscreen Body, Wuerzburg, Germany). FEV1 and VC were measured with a pneumotachograph (Jaeger Masterscreen Body). Resting daytime blood gases were measured in blood taken from the radial artery at midday with the patient breathing room air (Ciba-Corning 288 blood gas analyser, Medfield, MA, USA).

\section{Quality of life}

Quality of life was assessed using two validated health questionnaires: the St George's Respiratory Questionnaire (SGRQ) and the French version of the Nottingham Health 
Profile (FVNHP) [8-10]. The SGRQ was developed specifically for patients with severe COPD while the FVNHP is a general health questionnaire. The SGRQ [8] comprises 76 items which are weighted to produce three component scores (symptoms, activity, impacts) as well as a total score. The "symptoms" section is concerned with respiratory symptoms, their frequency and severity; the "activity" section is concerned with activities that cause or are limited by breathlessness; and the "impacts" section covers a range of aspects concerned with social functioning and psychological disturbances resulting from airways disease. The FVNHP [9, 10] contains 38 statements which are weighted to obtain six component scores (sleep, pain, energy, physical mobility, social isolation, and emotional reactions) and a total score.

\section{Statistical analysis}

Statistical analysis of all data was performed with the Wilcoxon signed rank test, with the level of significance set at $\mathrm{p}<0.05$.

\section{Results}

All patients completed 6 months of domiciliary NIPPV. Four patients complained of sleep disturbance with mechanical ventilation via the nasal mask and were placed on NIPPV for $5 \mathrm{~h}$ each day. The mean \pm SD duration of utilization of NIPPV by these patients was $4 \pm 1 \mathrm{~h}$. Ten patients completed 6 months of NIPPV; these patients used the machine for $8 \pm 2 \mathrm{~h}$ every night. Nasal mask intolerance was never a problem although six patients complained of nasal dryness and eight complained of gastro-intestinal distention due to air insufflation. Four patients presented one to three episodes of acute respiratory decompensation due to infectious bronchitis requiring admission to the respiratory intensive care unit. Two of these patients were on daytime NIPPV at home and two utilized domiciliary nocturnal NIPPV. Endotracheal mechanical ventilation was never necessary. All four patients responded favourably to medical therapy associating oxygen, administration of $\beta_{2}$-agonists by a nebulizer, antibiotics and positive pressure nasal ventilation using a volume preset ventilator (Servo $900 \mathrm{C}$, Siemens, Solna, Sweden) for $5 \mathrm{~h}$ sessions every $24 \mathrm{~h}$. The mean stay in the intensive care unit was $7 \pm 3$ days.

\section{Outcome measurements}

Lung function and blood gases. Blood gases measured using the ventilator during daytime and nocturnal NIPPV are listed in table 3. No significant improvements were noted in spirometric values or lung volumes over the course of the study, but significant changes were observed in daytime blood gas values. Daytime blood gas data over the study period are shown in table 2. Six months of NIPPV in addition to LTOT resulted in significant improvements in daytime $\mathrm{Pa}, \mathrm{O}_{2}$ and $\mathrm{Pa}, \mathrm{CO}_{2}$ compared to baseline values. $\mathrm{Pa}, \mathrm{O}_{2}$ rose from $7.8 \pm 0.7 \mathrm{kPa}$ at baseline to $9.0 \pm 0.9 \mathrm{kPa}$ at completion of the NIPPV study period $(\mathrm{p}=0.001)$. Mean $P \mathrm{a}, \mathrm{CO}_{2}$ decreased significantly, from $7.8 \pm 0.8 \mathrm{kPa}$ at baseline to $6.3 \pm 0.7 \mathrm{kPa}$ after 6 months
Table 3. - Blood gas measurements during nasal intermittent positive pressure ventilation (NIPPV)

\begin{tabular}{lcccc}
\hline & \multicolumn{2}{c}{ Daytime NIPPV } & \multicolumn{2}{c}{ Nocturnal NIPPV } \\
\cline { 2 - 5 } & $\begin{array}{c}\text { Following } \\
\text { NIPPV } \\
\text { acclimatiza- } \\
\text { tion }\end{array}$ & $\begin{array}{c}\text { Following } \\
\text { 6 months } \\
\text { of NIPPV }\end{array}$ & $\begin{array}{c}\text { Following } \\
\text { NIPPV } \\
\text { acclimatiza- } \\
\text { tion }\end{array}$ & $\begin{array}{c}\text { Following } \\
6 \text { of NIPPV } \\
\text { of NIP }\end{array}$ \\
\hline $\mathrm{pH}$ & $7.47 \pm 0.05$ & $7.43 \pm 0.03$ & $7.44 \pm 0.03$ & $7.44 \pm 0.06$ \\
$\mathrm{~Pa}_{\mathrm{a}, \mathrm{CO}_{2} \mathrm{kPa}}$ & $5.9 \pm 0.5$ & $5.9 \pm 0.1$ & $5.9 \pm 0.3$ & $6.1 \pm 0.8$ \\
$P \mathrm{a}, \mathrm{O}_{2} \mathrm{kPa}$ & $11.9 \pm 2.2$ & $11.1 \pm 1.8$ & $13 \pm 2.6$ & $12.9 \pm 2.4$ \\
\hline
\end{tabular}

Values are presented as mean $\pm \mathrm{S}$. $P \mathrm{a}_{\mathrm{a}} \mathrm{CO}_{2}$ : arterial carbon dioxide tension; $\mathrm{Pa}, \mathrm{O}_{2}$ : arterial oxygen tension.

of NIPPV ( $p=0.001$ ), vital capacity, FEV1, and total lung capacity (TLC) were all improved after 6 months of NIPPV, (VC $2.2 \pm 0.6$ to $2.5 \pm 0.7 \mathrm{~L}$; FEV1 $0.75 \pm 0.18$ to $0.77 \pm$ $0.18 \mathrm{~L}$; TLC $4.9 \pm 1.2$ to $5.1 \pm 1.3 \mathrm{~L}$ ) but these changes were not statistically significant. Comparison of blood gases for patients treated by nocturnal NIPPV versus daytime NIP$\mathrm{PV}$ revealed that $\mathrm{Pa}, \mathrm{CO}_{2}$ in the group treated at night decreased from $7.6 \pm 0.7 \mathrm{kPa}$ at entry to $6.1 \pm 0.5 \mathrm{kPa}$ after 6 months of treatment; this difference is statistically significant $(\mathrm{p}=0.007)$. In contrast, the decrease was nonsignificant in the group treated during the day.

Quality of life. Quality of life was assessed using the SGRQ and FVNHP questionnaires. The SGRQ provides individual scores for symptoms, activities, and psychosocial impacts and a total score derived from all three components. During the NIPPV study period, small but significant improvements were noted in impacts $(p=0.04)$ and the total score $(\mathrm{p}=0.04)$ compared to run-in values. Like the SGRQ, the FVNHP gives individual scores for sleep, energy, physical mobility, emotional reactions, pain and social isolation, plus a total score derived from all six components. During the NIPPV study period, FVNHP scores improved significantly for physical mobility $(\mathrm{p}=$ $0.02)$, emotional reactions $(\mathrm{p}=0.04)$ and energy $(\mathrm{p}=0.01)$. The total FVNHP score was also significantly improved $(p=0.007)$ with NIPPV. SGRQ and FVNHP results were expressed as a percentage of the maximum possible score, with a decrease reflecting improvement (figs. 1 and 2).

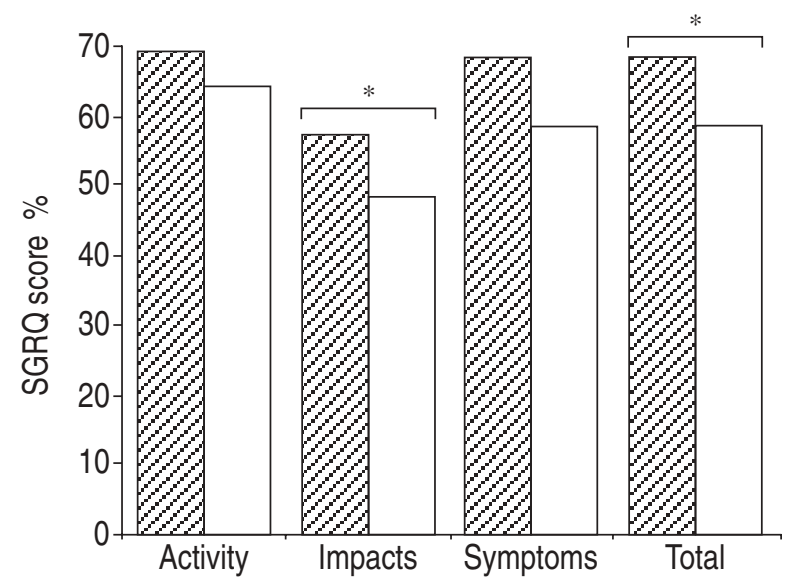

Fig. 1. - St George's Respiratory Questionnaire (SGRQ) scores. Values are presented as a percentage of the maximum possible score for patients using nasal intermittent positive pressure ventilation (NIPPV) for 6 months. $Q$ : SGRQ score before NIPPV; $\square$ : SGRQ score after 6 months of NIPPV. 


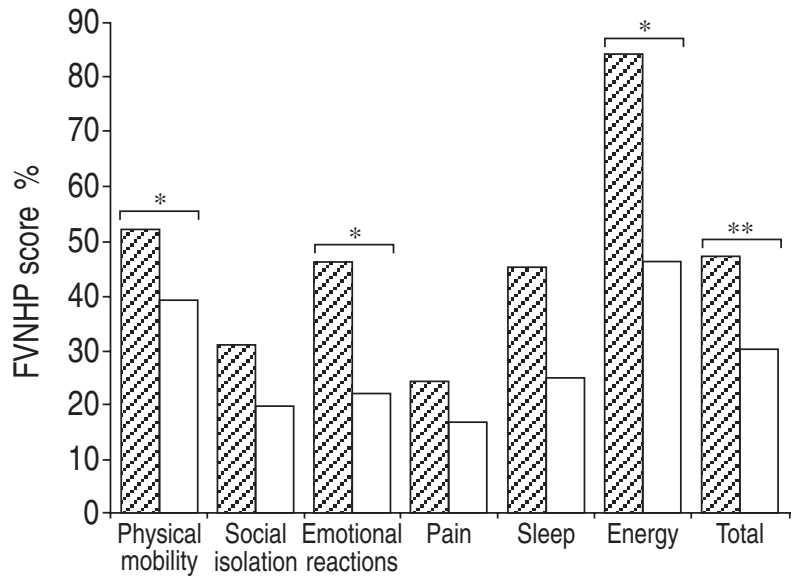

Fig. 2. - French Version of the Nottingham Health Profile (FVNHP). Values are presented as a percentage of the maximum possible score for patients using nasal intermittent positive pressure ventilation (NIPPV) for 6 months. $Z$ : FVNHP score before NIPPV; $\square$ : FVNHP score after 6 months of NIPPV. *: $\mathrm{p}<0.05 ; * *: \mathrm{p}<0.01$.

\section{Discussion}

The association of oxygen therapy and NIPPV at home for 6 months significantly improved blood gases and the quality of life of our stable hypercapnic patients with COPD. Our findings, however, conflict with data in other literature, as other authors question the efficacy of domiciliary NIPPV for use in patients with COPD $[3,11]$.

In their randomized prospective crossover study, STRUMPF $e t$ al. [5] treated 19 COPD patients by oxygen therapy plus NIPPV for 3 months and compared results with oxygen therapy alone for 3 months. These authors failed to observe any significant change in blood gases after 3 months of mechanical ventilation despite a significant improvement in cognitive functions.

LEGER et al. [12] described management of chronic hypercapnic respiratory failure by oxygen supplementation plus domiciliary NIPPV. In their study, 276 patients (105 kyphoscoliosis, 80 post-tuberculosis sequelae, 16 Duchenne muscular dystrophy, 50 COPD, 25 bronchiectasis) were followed-up for 5 yrs. COPD patients showed a significant reduction in $\mathrm{Pa}, \mathrm{CO}_{2}$ during spontaneous ventilation (SV) in the first and second years of treatment, but there was no related improvement in $\mathrm{Pa}, \mathrm{O}_{2}$. The authors attributed this to the wide variety of obstructive respiratory disorders caused by bronchial hypersecretion and chronic airways inflammation.

In their open prospective study, ElLIOTT et al. [6] investigated 12 hypercapnic COPD patients treated by domiciliary nocturnal mechanical ventilation for 6 months. Eight of their patients completed the protocol, and seven of the eight continued the treatment for $1 \mathrm{yr}$. One patient died early in the study and three were excluded because they were unable to tolerate nocturnal NIPPV. After $1 \mathrm{yr}$ of NIPPV, findings were similar to those of LEGER et al. [12]: $P \mathrm{a}, \mathrm{O}_{2}$ remained unchanged and $\mathrm{Pa}_{\mathrm{a}}, \mathrm{CO}_{2}$ had decreased significantly in SV.

Our study findings show that a combination of oxygen therapy plus NIPPV for 6 months can significantly improve $P \mathrm{a}, \mathrm{O}_{2}$ and $P \mathrm{a}, \mathrm{CO}_{2}$ in hypercapnic COPD patients in $\mathrm{SV}$. These results agree with those of Mевснам Jones et al. [7] who compared oxygen therapy alone for 3 months with oxygen therapy plus nocturnal NIPPV for 3 months in a randomized prospective crossover study of 14 hypercapnic COPD patients. These authors are the only ones to have reported significant improvements in $\mathrm{Pa}, \mathrm{O}_{2}$ and $P a, \mathrm{CO}_{2}$ during spontaneous ventilation after 3 months of treatment associating oxygen therapy and NIPPV.

It should be pointed out, however, that the criterion of ventilatory stability we used for inclusion was not as strict as that of ElLiorT et al. [6]. These last authors defined ventilatory stability as less than $5 \%$ variation in blood gas parameters and FEV1 for 1 month versus approximately $10 \%$ in our study. In addition, while the respiratory illnesses in our patients were less severe (mean \pm SD FEV1 $0.75 \pm 18 \mathrm{~L}$ ) than those of the subjects studied by STRuMPF $e t$ al. [5] (mean FEV1 $0.56 \pm 0.03$ L) or Eluiort et al. [6] (mean \pm SD FEV1 $0.60 \pm 0.25 \mathrm{~L}$ ), they were more severe than the disorders of the COPD patients investigated by MEECHAM JONEs et al. [7]) (mean \pm SD FEV1 0.86 $\pm 0.3 \mathrm{~L}$ ).

While these differences may help explain the significant improvement in blood gases noted in our study after 6 months of NIPPV, four of our patients were unable to adapt to nocturnal mechanical ventilation via nasal mask and required hourly daytime sessions; no significant improvement was seen in $P \mathrm{a}, \mathrm{CO}_{2}$ in spontaneous ventilation after 6 months of treatment. During the study, four other patients presented one to three episodes of acute respiratory decompensation due to infectious bronchitis requiring hospitalization in the intensive respiratory care unit, but this did not mask the improvement in the blood gas parameters of the study population as a whole.

The mechanisms by which long-term NIPPV improves blood gases in spontaneous breathing remain controversial. The respiratory muscles of COPD patients are subject to chronic fatigue owing to pulmonary hyperinflation caused by the obstructive ventilatory disorder [13] and to nocturnal respiratory acidosis which impairs the contractility of the diaphragm [14]. In COPD, NIPPV can reduce diaphragmatic electromyographic activity $[2,15]$ and can lighten the workload on the respiratory muscles [2]. However, the cause-effect relationship between respiratory muscle "rest" induced by nasal mask mechanical ventilation and improvement of blood gases in spontaneous breathing after a period of nasal ventilation has not been established in COPD [3, 7]. Moreover, prolonged nasal mask mechanical ventilation has never been shown to improve the strength or endurance of the respiratory muscles $[3,7]$.

The predominant mechanism behind improved blood gas tensions in spontaneous ventilation appears to be an increase in chemosensitivity to $\mathrm{CO}_{2}[3,16]$. Re-expansion of micro-atelectatic areas by positive pressure ventilation might contribute to improvement of blood gases in spontaneous ventilation [6]. The increase in the VC observed in our study, although statistically nonsignificant, may reflect this phenomenon.

The nasal mask was well tolerated by 10 patients but four others complained that it disturbed their sleep, and they were unable to use NIPPV on a nocturnal basis. Over half of our subjects (eight out of 14) suffered from gastrointestinal inflation caused by positive pressure mechanical ventilation. This adverse effect has been mentioned in over $50 \%$ of cases reported in the literature [1]. Gastric distension is reportedly less frequent when positive pressure ventilation is performed with an inspiratory muscle effort [1], but Meecham Jones and Wedzicha [17] failed to find 
this difference between volume preset ventilators and inspiratory muscle effort in their comparative study.

Hypoxaemia in patients with chronic respiratory failure causes multiple disturbances, such as impairment of cognitive functions, disruption of sleep architecture, and reduction of the walking distance, which in turn generates anxiety and depression [18-20]. While LTOT improves exercise tolerance $[21,22]$ and neuropsychological function [22], no objective improvement has been observed in the quality of life [20]. However, the questionnaires utilized to evaluate quality of life in patients on domiciliary oxygen therapy, such as the Sickness Impact Profile (SIP) and the Quality of Well-being Scale (QWB), merely provide measures of general health; they do not contain parameters specific to respiratory disease [19]. The fact that these questionnaires failed to find any correlation between hypoxaemia and alteration of quality of life in COPD contrasts with findings provided by the SGRQ, which was specifically designed to assess the quality of life of these patients [19].

Although our study was concerned with more severely ill patients (all were hypercapnic), an association of oxygen therapy and domiciliary NIPPV improved their quality of life, as revealed by the two health questionnaires used. The SGRQ, which has been specifically validated for COPD, and the FVNHP, both revealed a significant improvement in the patients' perception of their disease and the global quality-of-life score. The FVNHP also indicated a significant improvement in physical activity and energy; this difference with the SGRQ can be explained by the wide variety of responses possible with the FVNHP, a feature for which this questionnaire has been criticized [23]. While none of the other items evaluated by these two questionnaires improved significantly after 6 months of NIPPV, they did not deteriorate either, despite the cumbersome nature of the equipment and the difficulties involved in adaptation to ventilation by a nasal mask. Using the Chronic Respiratory Disease Questionnaire, ELLIOTT et al. [6] failed to find any significant difference in the dimensions dyspnoea, fatigue, emotional function or mastery after 6 months of mechanical ventilation by nasal mask. Our results are thus similar to those of MEECHAM JONES et al. [7], who were the first to observe a significant improvement in the quality of life in COPD after 3 months of NIPPV plus oxygen therapy using the SGRQ.

In our trial, a combination of oxygen therapy plus nasal intermittent positive pressure ventilation at home, improved blood gases in spontaneous ventilation as well as the quality of life of patients with chronic obstructive pulmo-nary disease. This is all the more interesting because four of our 14 patients required daytime mechanical ventilation for 6 months and this did not adversely affect the study group's respiratory function results or quality-of-life scores.

Acknowledgements: The authors would like to thank D. Veale for comments and criticisms and N. Rameau for assistance in the preparation of the manuscript.

\section{References}

1. Leger P. Noninvasive positive pressure ventilation at home. Respiratory Care 1994; 39: 501-510.

2. Elliott MW, Mulvey DA, Moxham J, Green M, Branthwaite MA. Inspiratory muscle effort during nasal intermittent positive pressure ventilation in patients with chronic obstructive airways disease. Anaesthesia 1993; 48: 8-13.
3. American Thoracic Society Statement. Standards for the diagnosis and care of patients with chronic obstructive pulmonary disease. Am J Respir Crit Care Med 1995; 152 : s78-s121.

4. Simonds AK, Elliott MW. Outcome of domiciliary nasal intermittent positive pressure ventilation in restrictive and obstructive disorders. Thorax 1995; 50: 604-609.

5. Strumpf DA, Millman RP, Carlisle CC, et al. Nocturnal positive-pressure ventilation via nasal mask in patients with severe chronic obstructive pulmonary disease. Am Rev Respir Dis 1991; 144: 1234-1239.

6. Elliott MW, Simonds AK, Carroll MP, Wedzicha JA, Branthwaite MA. Domiciliary nocturnal nasal intermittent positive pressure ventilation in hypercapnic respiratory failure due to chronic obstructive lung disease: effects on sleep and quality of life. Thorax 1992; 47: 342-348.

7. Meecham Jones DJ, Paul EA, Jones PW, Wedzicha JA. Nasal pressure support ventilation plus oxygen compared with oxygen therapy alone in hypercapnic COPD. Am J Respir Crit Care Med 1995; 152: 538-544.

8. Jones PW, Quirk FH, Baveystock CM. The St. George's Respiratory Questionnaire. Respiratory Medicine 1991; 85: 25-31.

9. Bucquet D, Condon S, Ritchie K. The French version of the Nottingham Health Profile: a comparison of items weights with those of the source version. Soc Sci Med 1990; 30: 829-835.

10. Hunt SM, McKenna SP, McEwen J, Williams J, Papp E. The Nottingham Health Profile: subjective health status and medical consultations. Soc Sci Med 1981; 15A: 221-229.

11. Hill NS. Noninvasive ventilation: does it work, for whom, and how? Am Rev Respir Dis 1993; 147: 1050-1055.

12. Leger P, Bedicam JM, Cornette A, et al. Nasal intermittent positive pressure ventilation: long-term follow-up in patients with severe chronic respiratory insufficiency. Chest 1994; 105: 100-105.

13. Roussos C, Macklem PT. The respiratory muscles. $N$ Engl J Med 1982; 307: 786-797.

14. Juan G, Calverley P, Talamo J, Schnader J, Roussos C. Effect of carbon dioxide on diaphragmatic function in human beings. $N$ Engl J Med 1984; 310: 874-879.

15. Ambrosino N, Nava S, Bertone P, Fracchia C, Rampulla C. Physiologic evaluation of pressure support ventilation by nasal mask in patients with stable COPD. Chest 1992; 101: 385-391.

16. Elliott MW, Mulvey DA, Moxham J, Green M, Branthwaite MA. Domiciliary nocturnal nasal intermittent positive pressure ventilation in COPD: mechanisms underlying changes in arterial blood gas tensions. Eur Respir J 1991; 4: 1044 1052.

17. Meecham Jones DJ, Wedzicha JA. Comparison of pressure and volume preset nasal ventilator systems in stable chronic respiratory failure. Eur Respir J 1993; 6: 1060-1064.

18. Guyatt GH, Berman LB, Townsend M, Pugsley SO, Chambers LW. A measure of quality of life for clinical trials in chronic lung disease. Thorax 1987; 42: 773-778.

19. Okubadejo AA, Jones PW, Wedzicha JA. Quality of life in patients with chronic obstructive pulmonary disease and severe hypoxaemia. Thorax 1996; 51: 44-47.

20. Jones PW. Quality of life: specific problems associated with hypoxaemia. Monaldi Arch Chest Dis 1993; 48: 565-573.

21. Vergeret J, Brambilla C, Mounier L. Portable oxygen therapy: use and benefit in hypoxaemic COPD patients on long term oxygen therapy. Eur Respir J 1989; 2: 20-25.

22. Nocturnal Oxygen Therapy Trial Group. Continuous or nocturnal oxygen therapy in hypoxaemic chronic obstructive lung disease. Ann Intern Med 1980; 93: 391-398.

23. Jessop EG. Confidence limits for Nottingham Health Profile scores: some empirical results. J Public Health Med 1990; 12: 141. 